\title{
Beta Endorphin Levels in PCOS Women: Relationship With Insulin Secretion
}

\author{
Lisa M. Pastore ${ }^{\mathrm{a}, \mathrm{f}}$, Patricia L. Dougherty ${ }^{\mathrm{a}, \mathrm{b}}$, Amelia P. Bailey ${ }^{\mathrm{a}, \mathrm{c}}$, \\ Anjie Lid ${ }^{\mathrm{d}}$, Allan H. Goldfarb
}

\begin{abstract}
Background: An understanding of the relationship between beta endorphin $(\beta E)$ with insulin, glucose and gonadotropins may explain how non-pharmacologic treatment options such as exercise and acupuncture may be beneficial to women with Polycystic Ovary Syndrome (PCOS). The objective was to examine the correlation of $\beta \mathrm{E}$ with insulin, glucose and gonadotropins, controlling for exercise and body mass index (BMI).
\end{abstract}

Methods: 40 untreated women with a confirmed diagnosis of PCOS (NIH criteria) were tested. Height, exercise frequency and exercise intensity were self-reported; weight was measured by nurses. Blood samples were collected for the biological measures of interest. The setting was an academic US medical center. Statistical analyses consisted of Spearman correlations and partial correlations with an alpha $=0.05$. The main outcome measures included plasma $\beta \mathrm{E}$, insulin and glucose (fasting and AUC) from a 2-hour oral glucose tolerance test, serum gonadotropins.

Results: The mean $\beta E$ level was $7.92 \mathrm{pmol} / \mathrm{mL}$ ( $\mathrm{sd}=4.0$, range 1.92 - 18.7, 25\%/75\% interquartile range 4.56 - 11.29). $\beta E$ was associated with $\log _{\mathrm{e}}$ AUC-insulin $(\mathrm{P}=0.04)$ after adjustment for

Manuscript accepted for publication February 3, 2012

a Obstetrics \& Gynecology Department, University of Virginia, Charlottesville, VA 22908, USA

${ }^{\mathrm{b}}$ Current address: Augusta Health Center, Fishersville, VA 22939 USA

${ }^{\mathrm{c} C u r r e n t}$ address: Center for Infertility and Reproductive Surgery,

Brigham and Women's Hospital, Boston, MA 02115 USA

${ }^{\mathrm{d} S}$ School of Medicine, University of Virginia, Charlottesville, VA 22908, USA

eDepartment of Kinesiology, University of North Carolina Greensboro, Greensboro, NC 27402, USA

${ }^{\mathrm{f}}$ Corresponding author: Lisa M. Pastore, P.O. Box 800712, Dept. of OB/GYN, Charlottesville, VA 22908-0712, USA.

Email: 1pastore@virginia.edu

doi:10.4021/jem62w exercise as measured via energy equivalents; this correlation was unaffected by additional control of BMI. No relationship between $\beta E$ and luteinizing hormone, the luteinizing hormone/follicle stimulating hormone ratio, or glucose was seen after accounting for BMI and exercise.

Conclusions: $\beta E$ was positively correlated with AUC-insulin after accounting for exercise. Future studies could investigate the affects of $\beta E$-potentiating therapies, such as exercise and acupuncture, in women with PCOS to determine how these changes in $\beta \mathrm{E}$ are related to insulin/glucagon balance.

Keywords: Beta endorphin; Polycystic ovary syndrome; Insulin; Exercise

\section{Introduction}

Polycystic ovary syndrome (PCOS), the most common endocrinopathy in women, is a heterogeneous condition which can present with varied clinical and biochemical characteristics [1]. Common features of PCOS, though not a requirement for diagnosis, include hyperandrogenism, oligomenorrhea, anovulation, an increased ratio of luteinizing hormone (LH) to follicle stimulating hormone (FSH) [2], insulin resistance, glucose intolerance, hirsutism, and a cystic appearance of the ovaries as seen with ultrasound.

There is increasing support for the concept that dysregulation of the endogenous opioid system contributes to the metabolic as well as the reproductive hormone abnormalities seen in PCOS. Normal $\beta E$ values in females with regular menses has been reported to be $4.4-4.73$ by one of the authors [3] and $2.9-4.3$ by others [4, 5] depending on whether the women were exercisers or sedentary. Several studies report higher levels of peripheral $\beta E$ in women with PCOS, especially in those who are obese [6], compared with women who do not have PCOS [7-9]. $\beta$ E has been implicated in blood glucose control during both rest $[10,11]$ and exercise [12-14] as $\beta E$ and opiate receptors have been isolated from sites that are involved in glucoregulation [15, $16]$. $\beta E$, an important part of the opioid system, was shown 
to increase in the circulation with exercise of sufficient intensity and duration $[17,18]$. Additionally, $\beta \mathrm{E}$ appears to play a role in metabolic regulation during exercise [13, 19, 20].

An intravenous bolus of beta endorphin $(\beta \mathrm{E})$ has been reported to result in an acute and simultaneous increase in both insulin and glucagon in normal and diabetic men and women $[21,22]$, although this only held true in obese subjects in articles that stratified by BMI $[23,24]$. Other studies have shown that administering an opioid antagonist results in a decrease in the insulin response to an oral glucose tolerance test in hyperinsulinemic, but not normoinsulinemic, women with PCOS [25-27]. Studies suggest that $\beta E$ is involved in the regulation of insulin secretion and carbohydrate metabolism in hyperandrogenic, hyperinsulinemic women [25, 28, 29].

In terms of the relationship between $\beta E$ and gonadotropin secretion, in healthy individuals $\beta E$ is considered a hypothalamic neurotransmitter which suppresses GnRH release and thus inhibits the release of LH [26]. In contrast, women with PCOS are observed to have increased peripheral $\beta \mathrm{E}$ levels [9] in concert with elevated LH levels [30]. Administration of an opioid antagonist leads to a normalization of the $\mathrm{LH}$ response to a GnRH challenge, although this effect seems to be limited to hyperinsulinemic women [29, 31], a category into which many PCOS patients fall.

PCOS is a complex disorder, and the pathogenesis is not fully understood. To date, there have been no other reports that considered the potential effects of exercise on $\beta \mathrm{E} / \mathrm{meta}-$ bolic/gondaoptropin relationships in women with PCOS. There is only one prior study reporting $\beta E$ 's relationship with the LH/FSH ratio [32]. This study aimed to expand upon the limited reports on the possible relationships of $\beta \mathrm{E}$ and insulin, glucose, LH, LH/FSH ratio in a cohort of PCOS women with an assessment of potential confounding from exercise and BMI.

\section{Methods}

The population studied was comprised of $n=40$ untreated women diagnosed with PCOS who had participated in a randomized clinical trial [33]. This publication is a crosssectional analysis of baseline data collected prior to any intervention. The University of Virginia (UVA) Institutional Review Board approved this protocol and all study participants provided an informed consent.

\section{Enrollment criteria}

PCOS was diagnosed using NICHD criteria [34]; namely, women had oligomenorrhea and hyperandrogenism (e.g., elevated free testosterone, hirsutism, or acne). Subjects had at least one menses in the previous six months, but no more than eight periods in the previous 12 months. Additional in- clusion criteria were an age between 18 and 43 years, and a weight of 250 pounds $(113 \mathrm{~kg})$ or less. All women had normal serum concentrations of prolactin, thyroid stimulating hormone, and 17-hydroxyprogesterone. No woman had used any hormonally-active intervention (e.g., metformin, hormonal contraceptives) in the prior 60 days. Free testosterone was calculated from testosterone and sex hormone blinding globulin levels (SHBG) [35] using "> $6.8 \mathrm{pg} / \mathrm{mL}$ " as the definition of an elevated level among females [36]. Exclusion criteria were: a) fasting blood glucose level $>125 \mathrm{mg} / \mathrm{dL}$, and b) hemoglobin A1C (HgbA1C) level $>6.0 \%$.

\section{Data sources}

Demographic, lifestyle and gravidity data were self-reported via questionnaire. A standard 2-hour oral glucose tolerance test was administered using a 75-gram glucose load (either glucola drink or jelly beans [37]) in a fasting state. The preintervention serum samples for LH and FSH were collected within 7 days of the self-reported last menstrual period (LMP) for 3 subjects; two women had mid-cycle samples drawn and were removed from the LH and LH/FSH data analysis. For the remaining 35 women, the median menstrual cycle day (CD) was 31 with an interquartile range of 18 38 days. Blood draws by trained nursing staff were taken at times 0, 30 (allowing 10 minutes for glucose consumption), 60, 90 and 120. Androgens were assayed on fasting blood samples collected for diagnostic purposes. All assays (except $\mathrm{HgbA} 1 \mathrm{C}$ and $\beta \mathrm{E}$ ) were run by the UVA General Clinical Research Center Core Lab using standard chemiluminescent enzyme-linked immunoassays. The analytical sensitivity of insulin was $2.0 \mathrm{mIU} / \mathrm{mL}$ with a intra-assay assay coefficient of variation $(\mathrm{CV})$ of $2.3 \%$ and an inter-assay $\mathrm{CV}$ of $8.0 \%$. The analytical sensitivity of FSH was $0.1 \mathrm{mIU} / \mathrm{mL}$ with a coefficient of variation (cv) of 5.6\% among normally ovulating females (mean $4.85 \mathrm{mIU} / \mathrm{mL}$ ) and $6.3 \% \mathrm{cv}$ for perimenopausal females (mean $15.4 \mathrm{mIU} / \mathrm{mL}$ ). The analytical sensitivity of LH was $0.05 \mathrm{mIU} / \mathrm{mL}$ with a $7.4 \% \mathrm{cv}$ at normal follicular phase levels (mean $11.3 \mathrm{IU} / \mathrm{L}$ ). $\mathrm{HgAlc}$ was run by the UVA Clinical Lab. Serum insulin samples were stored at $-80{ }^{\circ} \mathrm{C}$ and subsequently batch assayed with a RIA kit on the Immulite 2000 instrument. The minimum detection for insulin was $2.0 \mathrm{mIU} / \mathrm{mL}$. Height and weight were measured by a research nurse for all study participants.

\section{Lab assay technology - Beta endorphin}

The $\beta E$ samples were assayed in the Exercise Physiology Research Laboratory at the University of North Carolina Greensboro under the direction of Dr. Goldfarb. For these assays, exactly $5 \mathrm{ml}$ blood was collected in a pre-chilled 6 $\mathrm{ml}$ lavender tube containing $0.5 \mathrm{ml}$ Trasylol (aprotonin), the sample was cold centrifuged at $1600 \mathrm{rpm}$ for $15 \mathrm{~min}$, and then the plasma samples were frozen at -80 oC. The plasma 
Table 1. Demographics and Behavioral Characteristics of the Study Population $(n=40)$

\begin{tabular}{|c|c|}
\hline Factor & N (\%), or Mean (sd) and range \\
\hline Age & $27.5(\mathrm{sd}=6.61), 18-43$ years \\
\hline \multicolumn{2}{|l|}{ Race } \\
\hline White & $32(80 \%)$ \\
\hline Black or African-American & $4(10 \%)$ \\
\hline Asian or American Indian & $2(5 \%)$ \\
\hline Mixed & $2(5 \%)$ \\
\hline Hispanic & $2(5 \%)$ \\
\hline \multicolumn{2}{|l|}{ Prior pregnancy history } \\
\hline Nulligravida & $30(75 \%)$ \\
\hline 1 prior pregnancy & $3(7.5 \%)$ \\
\hline 2 prior pregnancies & $7(17.5 \%)$ \\
\hline Smoke & $5(13 \%)$ \\
\hline BMI & $29.4(\mathrm{sd}=6.40)$, range $18.6-43.1$ \\
\hline $\begin{array}{l}\text { Number of periods in the most recent } 12 \text { months } \\
\text { without medication }\end{array}$ & $5.1(\mathrm{sd}=2.23)$ \\
\hline Self-reported acne & $19(48 \%)$ \\
\hline Self-reported hirsutism & $30(75 \%)$ \\
\hline \multicolumn{2}{|l|}{ Exercise (38) } \\
\hline None & $6(15 \%)$ \\
\hline Some but less than national guidelines & $19(48 \%)$ \\
\hline Meets national guidelines & $15(37 \%)$ \\
\hline
\end{tabular}

samples (2 $\mathrm{ml}$ aliquot) were loaded onto pre-treated $\mathrm{C}-18$ columns (acetone $2 \mathrm{ml}$ and $10 \mathrm{ml} \mathrm{DD} \mathrm{H}_{2} \mathrm{O}$ ). The column was washed 2 times with $2 \mathrm{ml}$ of $4 \%$ acetic acid in distilled water. The endorphin was eluted off the column with $5 \mathrm{ml}$ of $0.2 \mathrm{M}$ hydrochloric acid/acetone $(25 / 75)$ in polypropylene tubes and taken to dryness in a speed vacuum centrifuge. The pellet was then resuspended in $0.300 \mu \mathrm{l} \beta \mathrm{E}$ assay buffer and the Elisa for this assay from ALPCO was followed. All procedures were according to ALPCO and compared to known standards (www.alpco.com/single.asp?CatNumber=13RB\%20301).

\section{Exercise classification}

Through a self-administered questionnaire, participants were asked six questions about their physical activity other than employment-related activities during the past month. The questions were based on the Behavioral Risk Factor Surveillance System survey [38]. The exercise intensity and average minutes of that physical activity were used to categorize each participant into one of three groups: those that had no physical activity outside of work, those who met the Department of Health and Human Services guidelines of "physically active" [39], and those that had some exercise but that did not meet the national guidelines. These three levels of daily exercise were coded as: $1=$ none, $2=$ some exercise but at a level below the recommendations, and $3=$ at or above recommended level.

These data were also transformed into metabolic equivalents, or METs, using a published compendium of physical activities [40]. For activities where the compendium provided a range of MET values, the midpoint was used. That classification was conducted independently by two authors, and reviewed by a third author in cases of disagreement. Similar to the method described by Mudd [41], the total exercise energy expenditure per week was calculated as the MET for that activity multiplied by the frequency per week and the duration of the activity (relative to 1 hour); the two most common physical activities per week were included in this calculation. 


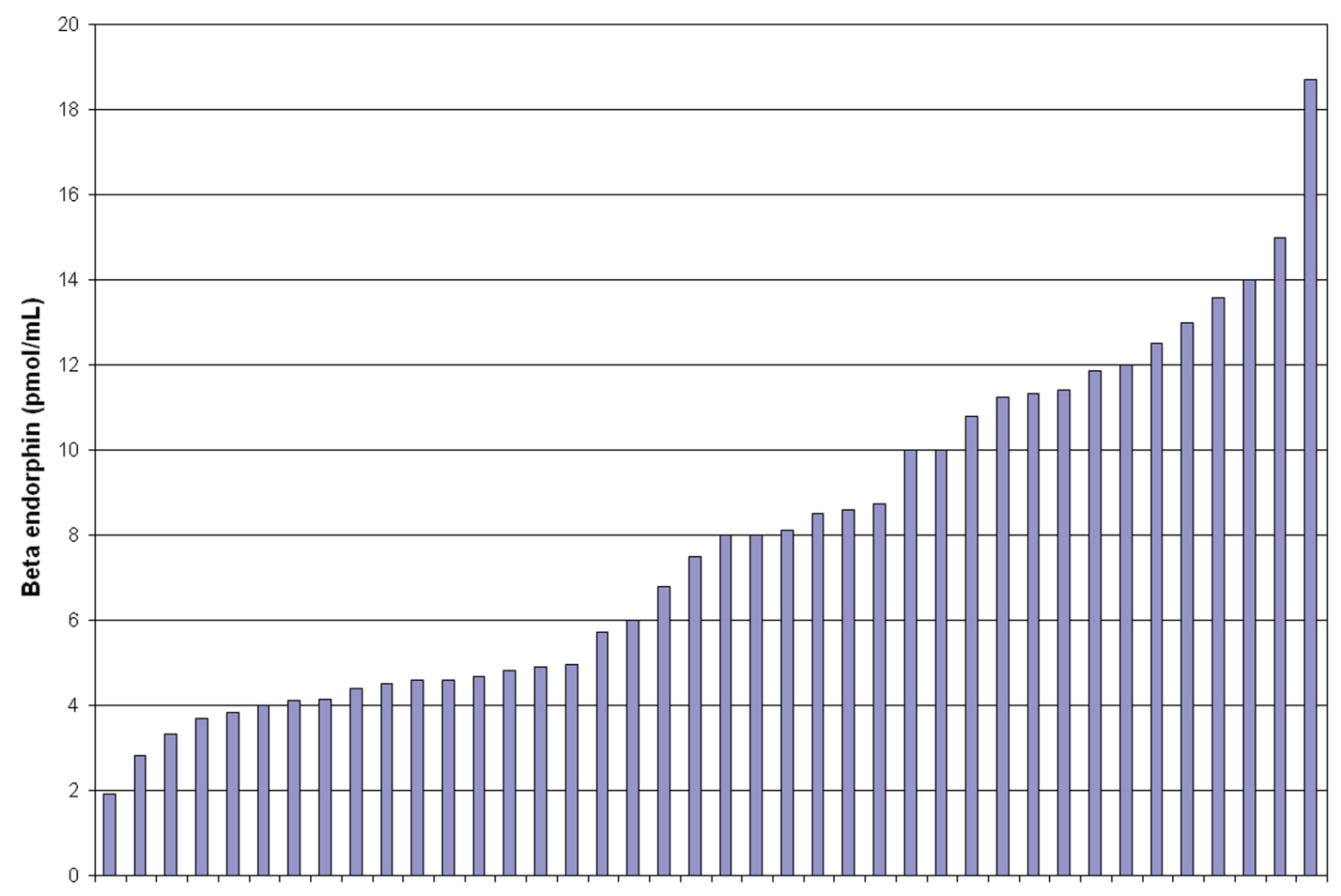

Figure 1. Beta Endorphin levels in 40 women with PCOS.

\section{Statistical analyses}

Spearman rank correlations were calculated to assess the relationship between $\beta \mathrm{E}$ with the six biological parameters of interest ( $\mathrm{LH}$, the $\mathrm{LH} / \mathrm{FSH}$ ratio, fasting insulin, area under the curve (AUC) insulin, fasting glucose, and AUC glucose). Graphs with lines-of-best-fit were developed. Based on limited prior research that indicated $\beta \mathrm{E}$ appeared to be greater in obese women with PCOS than non-obese women with PCOS $[6,32]$, the partial correlations were run controlling for BMI. As previously described, research has also demonstrated an influence on $\beta E$ levels from exercise, hence partial correlations were also run controlling for exercise. Finally, partial correlations were calculated controlling for both BMI and exercise.

All analyses were performed with SAS (version 9.2, Cary, NC). An alpha of 0.05 was considered statistically significant, and P-values between 0.05 and 0.10 were considered marginally significant. Given the relatively modest size of this cohort, marginally significant associations were noted in the text as areas for future investigation.

\section{Results}

This cohort contained a wide age range (18 to 43 years old) of women with PCOS, most of whom were Caucasian (Table 1). A broad BMI range was represented, with $37 \%(n=15)$ in the lean BMI category $(\mathrm{BMI}<25), 12 \%(\mathrm{n}=5)$ considered overweight $(25<\mathrm{BMI}<30)$, and the remaining $51 \%$ obese $(\mathrm{BMI}>30)$ [42]. The frequency of exercise in this cohort ranged from $15 \%$ without any regular exercise to $38 \%$ who met the US fitness guidelines.

As evidence of hyperandrogenemia, the androgen profile of the study participants was as follows. The mean testosterone was $58.2 \mathrm{ng} / \mathrm{dL}(\mathrm{sd}=28.52)$, and the mean DHEAS was $176.4 \mu \mathrm{g} / \mathrm{dL}(\mathrm{sd}=96.69)$. The mean free testosterone 13.28 $\mathrm{pg} / \mathrm{mL}(\mathrm{sd}=7.83)$, and the mean SHBG was $30.09 \mathrm{nmol} / \mathrm{liter}$ $(\mathrm{sd}=15.07)$.

The mean $\beta E$ level was $7.92 \mathrm{pmol} / \mathrm{mL}(\mathrm{sd}=4.0)$ for the entire cohort. The range was $1.92-18.7 \mathrm{pmol} / \mathrm{mL}$ with a $25 \% / 75 \%$ interquartile range of $4.56-11.29$. Figure 1 displays the distribution of all the individual $\beta E$ levels. Among the non-obese women $(n=20)$, the mean $\beta E$ level was 7.69 $\mathrm{pmol} / \mathrm{mL}(\mathrm{sd}=4.0)$ with the same interquartile range as for the full cohort. Among the obese sub-cohort $(n=20)$, the mean $\beta E$ level was $8.14 \mathrm{pmol} / \mathrm{mL}(\mathrm{sd}=4.1)$ with a $25 \% / 75 \%$ interquartile range of 4.61 - 10.71. $\beta \mathrm{E}$ was not correlated with BMI (as a continuous measure) in this cohort $(\mathrm{P}=0.66)$.

No bivariate correlation was observed between $\beta E$ and any of the six biological parameters of interest (Table 2). The scatterplots and lines-of-best-fit (Fig. 2), however, indicated a linear association between $\beta E$ and the natural log-transformed AUC-insulin results. Partial correlations controlling for BMI did not meaningfully improve the correlations. Partial correlations controlling for exercise (coded as a tri-level 
variable) increased the relationship between $\beta E$ and AUC insulin into the marginal significance range $(P=0.09)$, and this association was not strengthened when BMI was additionally controlled. When exercise was measured as the continuous energy expenditure variable, the partial correlation was strengthened between $\beta E$ and AUC insulin $(P=0.04)$, and this association was maintained when BMI was additionally controlled.

\section{Discussion}

This study found that $\beta E$ was significantly associated with AUC-insulin (after log transformation to ensure normality), after controlling for exercise expenditure levels in this PCOS cohort. This association was unaffected by control of BMI levels, and was weakened when exercise was measured as a categorical variable rather than as a continuous energy expenditure. There was no association between $\beta E$ and $\mathrm{LH}$, the $\mathrm{LH} / \mathrm{FSH}$ ratio, fasting insulin, fasting glucose, or AUC glucose. This is the first known report to include exercise as a potential confounder of these relationships. As reported previously by others [6-9], in our sample of women with PCOS the $\beta E$ levels were higher than in women without PCOS (published norms [4, 5] were used in this analysis for comparison).

The primary limitation of this study is the lack of a nonPCOS, BMI-matched control population. If a comparison population had been available, the analysis would have been able to comment on potential disease-mediated relationships separate from the effect of weight. A second limitation is that peripheral concentrations of BE were measured, rather than central levels, thus this study is not measuring central opioid tone. The latter is likely to have a stronger biological connection with the endocrine markers of interest than peripheral BE. Our sample size of 40 women is a strength relative to the literature, as is the wide range of BMI. There have been twelve prior publications on $\beta E$ levels in women with PCOS characteristics [6-9, 32, 43-49]. With two exceptions $[32,49]$, these reports had fewer than 20 PCOS study participants. An additional strength of our study is that endogenous $\beta \mathrm{E}$ was measured instead of an exogenous infusion of $\beta \mathrm{E}$, thus examining a normal physiologic state in women with PCOS versus an exogenous infusion. Furthermore, we also studied the relationship of $\beta \mathrm{E}$ with insulin, $\mathrm{LH}$, and the $\mathrm{LH} /$ FSH ratio along a continuum of BMI's rather than stratifying groups as "obese" versus "non-obese" thereby observing the effects of differing levels of obesity on $\beta E$, insulin, $\mathrm{LH}, \mathrm{LH} /$ FSH ratio in women with PCOS.

The previous reports on $\beta E$ in women with PCOS overall found that $\beta E$ levels were higher in women of greater body mass, both within PCOS and non-PCOS populations [6, 7, 32], and our findings concur (significant positive correlation between $\beta E$ and $\mathrm{BMI}, \mathrm{P}=0.0009$ ). In addition, we found a 

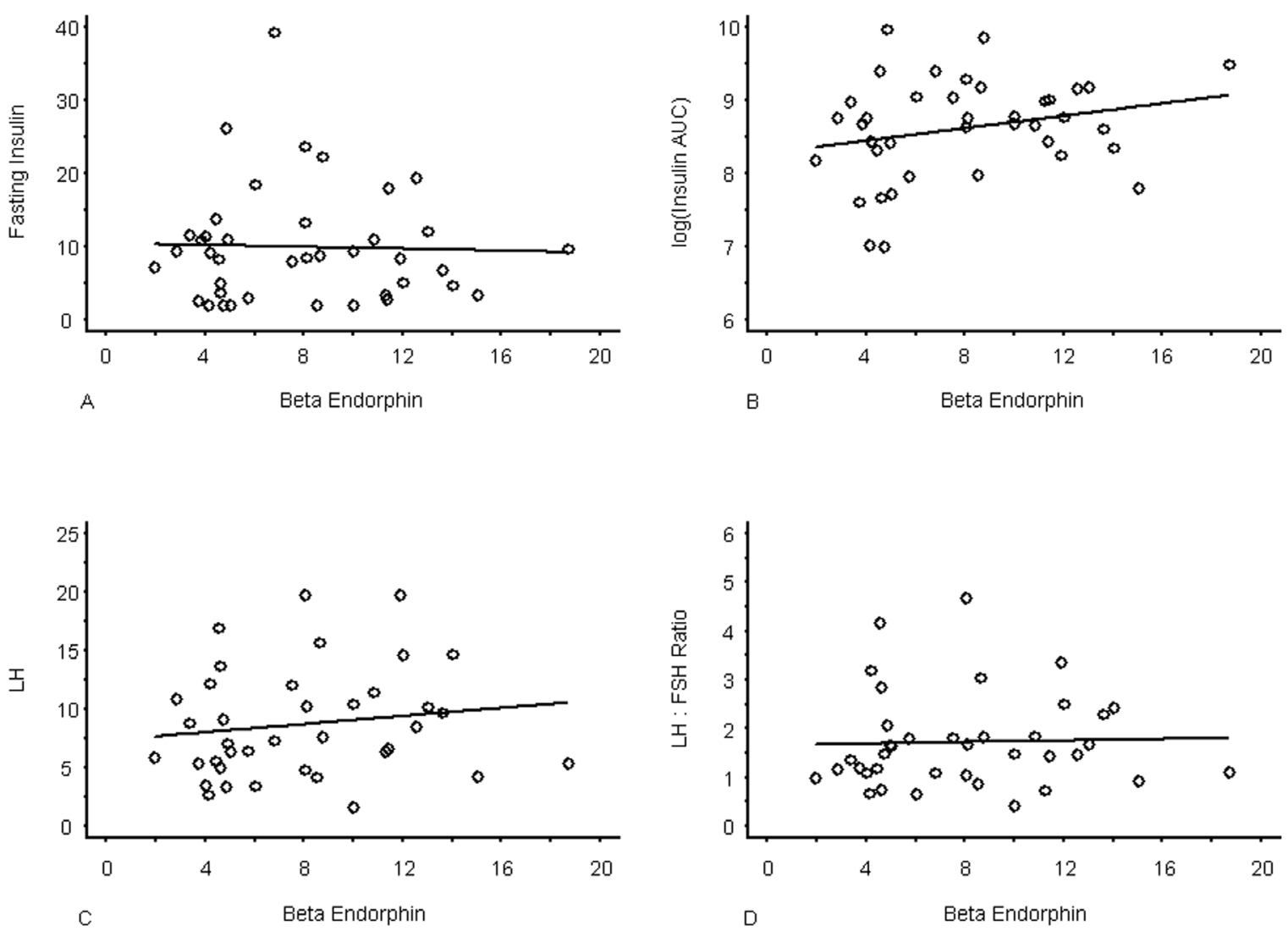

Figure 2. Graphs of Individual Observations of Beta endorphin by LH, LH/FSH Ratio, Insulin and log AUC-Insulin with Line-ofBest-Fit. $N=40$ for all measurements except $\mathrm{LH}$ and $\mathrm{LH} / \mathrm{FSH}$ ratio where the sample size was $\mathrm{n}=38$.

positive correlation between $\beta E$ and AUC-insulin even after controlling for BMI. This suggests that $\beta E$ itself could be potentiating the release of insulin after a glucose load. Our data is consistent with Laatkainen et al who observed this relationship in a sample size of eight women with PCOS [45].

To explore this further, we must first expound on recent understandings of insulin secretion. Rorsman et al discovered that b-islet cells studied in vitro showed insulin secretion as biphasic, the first phase being an acute degranulation occurring $\sim 1$ minute after extracellular addition of glucose, $5-10 \%$ of the total insulin was released in this fashion. The second phase starts at $\sim 5$ minutes with a steady stream of insulin secretion over a longer time course [50]. Rat studies have shown that $\beta E$ causes transient increases in insulin after glucose load $>150 \mathrm{mg} / \mathrm{dl}$ with effects lasting for $3-4$ minutes. This suggests that $\beta E$ may target first phase insulin release at sufficient glucose loads [51]. A mild correlation between $\beta E$ and AUC-insulin, such as our data shows, would be expected given that only $5-10 \%$ of circulating insulin in humans is released during the first phase. The relationship of $\beta \mathrm{E}$ and opioid receptors on insulin release, specifically the
K-ATPase/voltage gated Ca-channel pathway, could be explored via future research. Should an underlying pathophysiology be found explaining the relationship between $\beta \mathrm{E}$ and AUC-Insulin secretion, alternative treatments that modulate $\beta \mathrm{E}$ such as exercise or acupuncture $[52,53]$ may delay the need for or potentiate the effect of medications such as metformin.

Our results may suggest that at rest $\beta E$ exerts a potentiating effect on AUC-insulin. Several human and animal studies indicate that $\beta \mathrm{E}$ also exerts an effect on both insulin and glucagon at rest [11, 21, 54]. Previous rat studies [13] have shown that during exercise, a 6 - 7 fold increase in $\beta E$ actually resulted in higher plasma glucose levels. $\beta E$ maintenance infusion exacerbated the glucagon rise in exercised rats more so than in exercised rats that received a saline infusion. Clearly, the relationship between $\beta \mathrm{E}$ and glucose control is multi-factorial, and $\beta E$ may be involved in both physiologic insulin and glucagon maintenance. A direct effect of $\beta E$ on glucose homeostasis is implied by studies that found that an intravenous bolus of $\beta \mathrm{E}$ resulted in an acute and simultaneous increase in both insulin and glucagon in normal and dia- 
betic $[21,22]$ men and women, although this only held true in obese subjects in studies that stratified by BMI $[23,24]$. It may be worthwhile to study the effects of varying intensities of exercise on $\beta E$, and its subsequent effect on insulin and LH. This may lead to the development of therapeutic exercise regimens specifically designed for women with PCOS.

One prior study examined the relationship between $\beta \mathrm{E}$ with both insulin and LH in a single cohort of 137 women with PCOS (117 lean and 50 non-lean) [32]. They reported a significant inverse association between $\beta \mathrm{E}$ and $\mathrm{LH}(\mathrm{r}$ $=-0.173, \mathrm{P}=0.025)$ and a significant positive correlation between $\beta \mathrm{E}$ and fasting insulin $(\mathrm{r}=0.266, \mathrm{P}=0.002)$. They did not investigate AUC-insulin. Our cohort does not concur with their observations. Similarly, a different study with 64 subjects with PCOS [49] found an inverse association between $\beta \mathrm{E}$ and the $\mathrm{LH}$ to $\mathrm{FSH}$ ratio $(\mathrm{r}=-0.32 ; \mathrm{P}=0.015)$ whereas we found no correlation between the two. These differences could be due to the increased power of those studies, but, alternatively or additionally, our control of BMI and exercise level may underlie the variation in results across studies.

The association between $\beta \mathrm{E}$ and AUC-insulin only after controlling for exercise is worthy of additional discussion. Circulating $\beta \mathrm{E}$ increases have been reported in response to both aerobic and anaerobic exercise [19]. This increase in circulating $\beta E$ depends on exercise intensity $[17,55]$ and duration $[17,56]$, which supports the fact that the statistical significance of our observation strengthened when exercise energy equivalents were measured. A critical minimum intensity of $>60 \%$ of $\mathrm{VO}_{2}$ max appears to be needed to result in $\beta E$ elevation with aerobic exercise $[17,57,58]$. Resistance exercise of sufficient intensity and volume (workload) can also result in a transient increase in $\beta E$ levels within the circulation [55]. It should be noted that these elevations in $\beta \mathrm{E}$ levels are transitory and return to baseline levels in a relatively short time after the exercise is completed. Further studies could be conducted to determine how these changes in $\beta \mathrm{E}$ observed during exercise are related to the insulin/glucagon balance, particularly investigating what affect different exercise regimens have on the relationship between $\beta \mathrm{E}$ with insulin and glucagon in women with PCOS.

\section{Conclusion}

As the most common endocrinopathy effecting women, very little is known about the underlying mechanisms of PCOS. Evidence shows that $\beta E$ is involved in the regulation of insulin secretion and carbohydrate metabolism in hyperandrogenic, hyperinsulinemic women. Our study aimed to observe what, if any, relationship $\beta \mathrm{E}$ had on insulin, glucose, $\mathrm{LH}$, and the $\mathrm{LH} / \mathrm{FSH}$ ratio in women with PCOS. After accounting for exercise energy expenditures, $\beta \mathrm{E}$ was found to be significantly positively correlated with AUC-insulin $(\mathrm{P}=0.04)$. In light of the relatively new understanding of the delivery of insulin, we hypothesize $\beta E$ may be potentiating first phase, post-prandial insulin secretion. No relationship between $\beta \mathrm{E}$ and $\mathrm{LH}$, the $\mathrm{LH} / \mathrm{FSH}$ ratio, or glucose was seen after accounting for BMI and exercise frequency. As discussed, our findings provide several future avenues of research that may relate to therapeutic exercise regimens, or modalities such as acupuncture with a documented impact on $\beta \mathrm{E}$, to improve the endocrine and metabolic profile of women with PCOS.

\section{Acknowledgement}

The authors thank Dr. Christopher McCartney for his helpful comments on an earlier version of this manuscript, and James Patrie, MS, for his graphing assistance.

\section{Financial Acknowledgement}

This study was funded by grant number R21 AT002520 from the National Center for Complementary and Alternative Medicine (NCCAM) at the National Institutes of Health, and Grant Number M01RR000847 from the National Center for Research Resources. The content is solely the responsibility of the authors and does not necessarily represent the official views of the National Center for Research Resources, NCCAM or the National Institutes of Health. US Clinical Trials government registry, www.clinicaltrials.gov, NCT00602940

\section{Disclosure Statement}

The authors have nothing to disclose.

\section{References}

1. Use of insulin-sensitizing agents in the treatment of polycystic ovary syndrome. Fertil Steril. 2008;90(5 Suppl):S69-73.

2. Berga S, Daniels T. Use of the laboratory in disorders of reproductive neuroendocrinology. Journal of Clinical Immunoassay. 1991;14:23-8.

3. Goldfarb AH, Jamurtas AZ, Kamimori GH, Hegde S, Otterstetter R, Brown DA. Gender effect on beta-endorphin response to exercise. Med Sci Sports Exerc. 1998;30(12):1672-1676.

4. Harber VJ, Sutton JR, MacDougall JD, Woolever CA, Bhavnani BR. Plasma concentrations of beta-endorphin in trained eumenorrheic and amenorrheic women. Fertil Steril. 1997;67(4):648-653.

5. Hohtari H, Elovainio R, Salminen K, Laatikainen T. Plasma corticotropin-releasing hormone, corticotropin, and endorphins at rest and during exercise in eumenorrheic 
and amenorrheic athletes. Fertil Steril. 1988;50(2):233238.

6. Nappi C, Petraglia F, Cudemo V, Volpe A, Facchinetti F, Genazzani AR, Montemagno U. Plasma beta-endorphin levels in obese and non-obese patients with polycystic ovarian disease. Eur J Obstet Gynecol Reprod Biol. 1989;30(2):151-156.

7. Givens JR, Wiedemann E, Andersen RN, Kitabchi AE. beta-Endorphin and beta-lipotropin plasma levels in hirsute women: correlation with body weight. J Clin Endocrinol Metab. 1980;50(5):975-976.

8. Aleem FA, McIntosh T. Elevated plasma levels of betaendorphin in a group of women with polycystic ovarian disease. Fertil Steril. 1984;42(5):686-689.

9. Wortsman J, Wehrenberg WB, Gavin JR, 3rd, Allen JP. Elevated levels of plasma beta-endorphin and gamma 3 -melanocyte stimulating hormone in the polycystic ovary syndrome. Obstet Gynecol. 1984;63(5):630-634.

10. Giugliano D, Torella R, Lefebvre PJ, D’Onofrio F. Opioid peptides and metabolic regulation. Diabetologia. 1988;31(1):3-15.

11. Matsumura M, Fukushima T, Saito H, Saito S. In vivo and in vitro effects of beta-endorphin on glucose metabolism in the rat. Horm Metab Res. 1984;16(1):27-31.

12. Hickey MS, Trappe SW, Blostein AC, Edwards BA, Goodpaster B, Craig BW. Opioid antagonism alters blood glucose homeostasis during exercise in humans. J Appl Physiol. 1994;76(6):2452-2460.

13. Fatouros IG, Goldfarb AH, Jamurtas AZ, Angelopoulos TJ, Gao J. Beta-endorphin infusion alters pancreatic hormone and glucose levels during exercise in rats. Eur $\mathrm{J}$ Appl Physiol Occup Physiol. 1997;76(3):203-208.

14. Farrell PA, Sonne B, Mikines K, Galbo H. Stimulatory role for endogenous opioid peptides on postexercise insulin secretion in rats. J Appl Physiol. 1988;65(2):744749.

15. Bruni JF, Watkins WB, Yen SS. beta-Endorphin in the human pancreas. J Clin Endocrinol Metab. 1979;49(4):649-651.

16. Govoni S, Hanbauer I, Hexum TD, Yang HY, Kelly GD, Costa E. In vivo characterization of the mechanisms that secrete enkephalin-like peptides stored in dog adrenal medulla. Neuropharmacology. 1981;20(7):639-645.

17. Goldfarb AH, Hatfield BD, Armstrong D, Potts J. Plasma beta-endorphin concentration: response to intensity and duration of exercise. Med Sci Sports Exerc. 1990;22(2):241-244.

18. McMurray RG, Forsythe WA, Mar MH, Hardy CJ. Exercise intensity-related responses of beta-endorphin and catecholamines. Med Sci Sports Exerc. 1987;19(6):570574.

19. Goldfarb AH, Jamurtas AZ. Beta-endorphin response to exercise. An update. Sports Med. 1997;24(1):8-16.

20. Angelopoulos TJ, Denys BG, Weikart C, Dasilva SG,
Michael TJ, Robertson RJ. Endogenous opioids may modulate catecholamine secretion during high intensity exercise. Eur J Appl Physiol Occup Physiol. 1995;70(3):195-199.

21. Reid RL, Yen SS. beta-Endorphin stimulates the secretion of insulin and glucagon in humans. J Clin Endocrinol Metab. 1981;52(3):592-594.

22. Feldman M, Kiser RS, Unger RH, Li CH. Beta-endorphin and the endocrine pancreas. Studies in healthy and diabetic human beings. N Engl J Med. 1983;308(7):349353.

23. Giugliano D, Cozzolino D, Salvatore T, Ceriello A, Torella R, Franchimont P, Lefebvre PJ, et al. Physiological elevations of plasma beta-endorphin alter glucose metabolism in obese, but not normal-weight, subjects. Metabolism. 1992;41(2):184-190.

24. Giugliano D, Cozzolino D, Torella R, Lefebvre PJ, Franchimont P, D'Onofrio F. Persistence of altered metabolic responses to beta-endorphin after normalization of body weight in human obesity. Acta Endocrinol (Copenh). 1991;124(2):159-165.

25. Guido M, Pavone V, Ciampelli M, Murgia F, Fulghesu AM, Apa R, Caruso A, et al. Involvement of ovarian steroids in the opioid-mediated reduction of insulin secretion in hyperinsulinemic patients with polycystic ovary syndrome. J Clin Endocrinol Metab. 1998;83(5):17421745.

26. Fruzzetti F, Bersi C, Parrini D, Ricci C, Genazzani AR. Effect of long-term naltrexone treatment on endocrine profile, clinical features, and insulin sensitivity in obese women with polycystic ovary syndrome. Fertil Steril. 2002;77(5):936-944.

27. Fulghesu AM, Lanzone A, Cucinelli F, Caruso A, Mancuso $\mathrm{S}$. Long-term naltrexone treatment reduces the exaggerated insulin secretion in patients with polycystic ovary disease. Obstet Gynecol. 1993;82(2):191-197.

28. Hadziomerovic D, Rabenbauer B, Wildt L. Normalization of hyperinsulinemia by chronic opioid receptor blockade in hyperandrogenemic women. Fertil Steril. 2006;86(3):651-657.

29. Lanzone A, Fulghesu AM, Cucinelli F, Ciampelli M, Caruso A, Mancuso S. Evidence of a distinct derangement of opioid tone in hyperinsulinemic patients with polycystic ovarian syndrome: relationship with insulin and luteinizing hormone secretion. J Clin Endocrinol Metab. 1995;80(12):3501-3506.

30. Eyvazzadeh AD, Pennington KP, Pop-Busui R, Sowers M, Zubieta JK, Smith YR. The role of the endogenous opioid system in polycystic ovary syndrome. Fertil Steril. 2009;92(1):1-12.

31. Lanzone A, Apa R, Fulghesu AM, Cutillo G, Caruso A, Mancuso S. Long-term naltrexone treatment normalizes the pituitary response to gonadotropin-releasing hormone in polycystic ovarian syndrome. Fertil Steril. 
1993;59(4):734-737.

32. Martinez-Guisasola J, Guerrero M, Alonso F, Diaz F, Cordero J, Ferrer J. Plasma beta-endorphin levels in obese and non-obese patients with polycystic ovary disease. Gynecol Endocrinol. 2001;15(1):14-22.

33. Pastore LM, Williams CD, Jenkins J, Patrie JT. True and sham acupuncture produced similar frequency of ovulation and improved LH to FSH ratios in women with polycystic ovary syndrome. J Clin Endocrinol Metab. 2011;96(10):3143-3150.

34. Revised 2003 consensus on diagnostic criteria and longterm health risks related to polycystic ovary syndrome. Fertil Steril. 2004;81(1):19-25.

35. Vermeulen A, Verdonck L, Kaufman JM. A critical evaluation of simple methods for the estimation of free testosterone in serum. J Clin Endocrinol Metab. 1999;84(10):3666-3672.

36. ARUP Laboratories Lab Guide. Salt Lake City, UT [cited 2003 June 11]; Available from: http://www.aruplab. com/guides/clt/tests/clt_212b.htm

37. Lamar ME, Kuehl TJ, Cooney AT, Gayle LJ, Holleman S, Allen SR. Jelly beans as an alternative to a fifty-gram glucose beverage for gestational diabetes screening. Am J Obstet Gynecol. 1999;181(5 Pt 1):1154-1157.

38. Brown DW, Balluz LS, Heath GW, Moriarty DG, Ford ES, Giles WH, Mokdad AH. Associations between recommended levels of physical activity and health-related quality of life. Findings from the 2001 Behavioral Risk Factor Surveillance System (BRFSS) survey. Prev Med. 2003;37(5):520-528.

39. US_Department_of_Health_and_Human_Services. 2008 Physical Activity Guidelines for Ämericans. Hyattsville, MD: US Department of Health and Human Services2008.

40. Ainsworth BE, Haskell WL, Whitt MC, Irwin ML, Swartz AM, Strath SJ, O'Brien WL, et al. Compendium of physical activities: an update of activity codes and MET intensities. Med Sci Sports Exerc. 2000;32(9 Suppl):S498-504.

41. Mudd LM, Rafferty AP, Reeves MJ, Pivarnik JM. Physical activity recommendations: an alternative approach using energy expenditure. Med Sci Sports Exerc. 2008;40(10):1757-1763.

42. Department of Health and Human Services. National Institutes of Health. Calculate your body mass index. Available from: http://nhlbisupport.com/bmi/.

43. Tropeano G, Lucisano A, Liberale I, Barini A, Vuolo IP, Martino G, Menini E, et al. Insulin, C-peptide, androgens, and beta-endorphin response to oral glucose in patients with polycystic ovary syndrome. J Clin Endocrinol Metab. 1994;78(2):305-309.

44. National Heart Lung and Blood Institute. Obesity education initiative clinical guidelines on the identification, evaluation, and treatment of overweight and obesity in adults: the evidence report. Bethesda, MD: National Institutes of Health, National Heart, Lung and Blood Institute; 1998.

45. Laatikainen TJ, Tiitinen AE, Salminen-Lappalainen KR, Pekonen F. Response of plasma beta-endorphin and insulin to oral glucose tolerance test in non-obese women with polycystic ovaries. Gynecol Endocrinol. 1989;3(3):241-247.

46. Wu XK, Wang CH, Su YH. Responses of somatostatin, beta-endorphin and dynorphin A to a glucose load in two groups of women with polycystic ovarian syndrome. Horm Res. 1996;46(2):59-63.

47. Carmina E, Ditkoff EC, Malizia G, Vijod AG, Janni A, Lobo RA. Increased circulating levels of immunoreactive beta-endorphin in polycystic ovary syndrome is not caused by increased pituitary secretion. Am J Obstet Gynecol. 1992;167(6):1819-1824.

48. Laatikainen T, Salminen K, Virtanen T, Apter D. Plasma beta-endorphin, beta-lipotropin and corticotropin in polycystic ovarian disease. Eur J Obstet Gynecol Reprod Biol. 1987;24(4):327-333.

49. Martinez-Guisasola J, Ferrer J, Guerrero M, Diaz F, Alonso F, Bodega A, Cordero J, et al. Circulating levels of immunoreactive beta-endorphin in polycystic ovary syndrome. Gynecol Endocrinol. 1999;13(1):26-35.

50. Rorsman P, Renstrom E. Insulin granule dynamics in pancreatic beta cells. Diabetologia. 2003;46(8):10291045.

51. Curry DL, Bennett LL, Li CH. Stimulation of insulin secretion by beta-endorphins (1-27 \& 1-31). Life Sci. 1987;40(21):2053-2058.

52. Kiser RS, Khatami MJ, Gatchel RJ, Huang XY, Bhatia $\mathrm{K}$, Altshuler KZ. Acupuncture relief of chronic pain syndrome correlates with increased plasma met-enkephalin concentrations. Lancet. 1983;2(8364):1394-1396.

53. Hsu DT. Acupuncture. A review. Reg Anesth. 1996;21(4):361-370.

54. Schleicher RL, Chawla RK, Coan PA, Martino-Saltzman D, Collins DC. Beta-endorphin-induced hyperglycemia in rabbits: effects of a glucose or arginine challenge. Am J Physiol. 1987;252(2 Pt 1):E255-259.

55. Kraemer WJ, Dziados JE, Marchitelli LJ, Gordon SE, Harman EA, Mello R, Fleck SJ, et al. Effects of different heavy-resistance exercise protocols on plasma beta-endorphin concentrations. J Appl Physiol. 1993;74(1):450459.

56. Heitkamp HC, Huber W, Scheib K. beta-Endorphin and adrenocorticotrophin after incremental exercise and marathon running--female responses. Eur J Appl Physiol Occup Physiol. 1996;72(5-6):417-424.

57. Goldfarb AH, Hatfield BD, Potts J, Armstrong D. Beta-endorphin time course response to intensity of exercise: effect of training status. Int J Sports Med. 1991;12(3):264-268. 
58. Rahkila P, Laatikainen T. Effect of oral contraceptives on plasma beta-endorphin and corticotropin at rest and during exercise. Gynecol Endocrinol. 1992;6(3):163166. 